\title{
Indomethacin-induced gut damage in a surrogate insect model, Galleria mellonella
}

\author{
Helena Emery ${ }^{1} \cdot$ Richard Johnston $^{2} \cdot$ Andrew F. Rowley $^{1} \cdot$ Christopher J. Coates $^{1}$ (I)
}

Received: 1 May 2019 / Accepted: 26 June 2019 / Published online: 3 July 2019

(c) The Author(s) 2019

\begin{abstract}
Indomethacin is a non-steroidal anti-inflammatory drug that causes gastric ulceration and increased 'leakiness' in rat models, and is used routinely as a toxicology assay to screen novel compounds for repair and restitution properties. We set out to establish conditions for indomethacin-induced gut damage in wax-moth (Galleria mellonella) larvae with a view to reducing the need for rodents in such experimentation. We administered indomethacin $(0.5-7.5 \mu \mathrm{g} / \mathrm{larva} ; 2-30 \mathrm{mg} / \mathrm{kg})$ to G. mellonella via intrahaemocoelic injection and gavage (force-feeding) and monitored survival and development, blood cell (haemocyte) numbers, and changes in gut permeability. Increased levels of gut leakiness were observed within the first 4 - to $24 \mathrm{~h}$ by tracking fluorescent microspheres in the faeces and haemolymph (blood equivalent). Additionally, we recorded varying levels of tissue damage in histological sections of the insect midgut, including epithelial sloughing and cell necrosis. Degeneration of the midgut was accompanied by significant increases in detoxification-associated activities (superoxide dismutase and glutathione-S-transferase). Herein, we present the first evidence that G. mellonella larvae force-fed indomethacin display broad symptoms of gastric damage similar to their rodent counterparts.
\end{abstract}

Keywords Innate immunity $\cdot$ Gastrointestinal damage $\cdot$ Histopathology $\cdot$ Rodent models $\cdot$ Gavage $\cdot$ Gut leakiness $\cdot$ Eicosanoids

\section{Introduction}

When considering more carefully our use of vertebrates in disease and toxicology experimentation, there is constant need to develop alternative model systems in vitro, in vivo or in silico. One such in vivo alternative is the larvae of the greater wax-moth, Galleria mellonella. These insects are now used widespread as 'mini-hosts' for the investigation of microbial pathogenicity (Mowlds et al. 2010; Kloezen et al. 2015; Lim et al. 2018; Cools et al. 2019), screening of xenobiotics/toxins (Allegra et al. 2018; Coates et al. 2019) and functional

Electronic supplementary material The online version of this article (https://doi.org/10.1007/s00204-019-02508-4) contains supplementary material, which is available to authorized users.

Christopher J. Coates

c.j.coates@swansea.ac.uk

1 Department of Biosciences, College of Science, Swansea University, Swansea SA2 8PP, Wales, UK

2 Advanced Imaging Materials (AIM) Facility, Materials Research Centre, College of Engineering, Swansea University, Swansea SA1 8EN, Wales, UK characterisation of virulence factors (Altincicek et al. 2007; Champion et al. 2016). Larvae of G. mellonella are designated a non-animal technology (Allegra et al. 2018), which means there are fewer ethical restrictions and regulations compared to vertebrates. Additionally, practical advantages include low maintenance costs, thermal tolerance to $37^{\circ} \mathrm{C}$, ease of use (accurate dosages) and high turnover-results can be obtained within $72 \mathrm{~h}$-in contrast to vertebrates. Although G. mellonella have been used to study the infectivity of gut pathogens such as Campylobacter jejuni (Senior et al. 2011), Listeria monocytogenes (Mukherjee et al. 2013a), Vibrio spp. (Wagley et al. 2018), Shigella spp. (Barnoy et al. 2017) and Salmonella enterica (Card et al. 2016), there remains a distinct lack of information regarding the alimentary canal of this insect and its role in pathogenesis.

From mouth to rectum, the digestive system of lepidopteran larvae (like G. mellonella) consists of three distinct regions: the foregut (stomatodaeum), midgut (mesenteron) and hindgut (proctodaeum) (Engel and Moran 2013; Linser and Dinglasan 2014). The midgut is the primary site of digestion and absorption in many insects, and importantly, it lacks the exoskeletal/chitin lining seen in the fore- and 
hind-guts. The basic tissue architecture of the midgut is similar to those found in the human intestine, such as epithelial arrangements of columnar cells and smooth septate junctions that control permeability-analogous to tight junctions (Green et al. 1980). The insect peritrophic matrix is the functional equivalent to the mammalian mucus layer, which acts as a barrier for the epithelial cells and impedes pathogen movement into the body cavity (i.e., the haemocoel) (Campbell et al. 2008; Kuraishi et al. 2011). Moreover, some microbial communities characterised in the midgut of $G$. mellonella are similar to those found in crypts of the human intestine (Mukherjee et al. 2013b).

Non-steroidal anti-inflammatory drugs (NSAIDs) are used extensively to alleviate pain by inhibiting the activities of cyclooxygenase isozymes (COX1, COX2), yet known side effects manifest in gastrointestinal injury (Playford et al. 1999; Brune and Patrignani 2015). In particular, indomethacin causes ulceration by inducing apoptosis, reducing gastric blood flow and activating innate immune cells (neutrophils), which all contribute to mucosal secretion, maintenance and defence (Marchbank et al. 2011; Matsui et al. 2011). Gastric complications arising from indomethacin exposure have been developed into a standard rodent restraint/ulcer assay to screen novel compounds and health food supplements for putative therapeutic properties-tissue repair and restitution (Aguwa 1985; Playford et al. 1999, 2001; Mahmood et al. 2007). The adverse effects of indomethacin, notably inflammation, permeability and REDOX imbalance, have been studied thoroughly in humans and rodents (Basivireddy et al. 2003; Bjarnason and Takeuchi 2009; Sigthorsson et al. 2000; Perron et al. 2013). Therefore, we set out to interrogate the effects of indomethacin on the alimentary canal of G. mellonella. First, we utilised two inoculation methods (intrahaemocoelic injection and gavage) to assess the relative toxicity of indomethacin in insect larvae across the concentration range, $0.5-7.5 \mu \mathrm{g} / \mathrm{larva}$. Second, we combined histopathology screening, X-ray microtomography/ microscopy (XRM) and enzyme activities to assess the integrity of the midgut tissues in the absence and presence of this NSAID. Indomethacin treatments were established by extrapolating from Marchbank et al. (2011), wherein a dose of $20 \mathrm{mg} / \mathrm{kg}$ was administered to induce gastric damage in rats - the equivalent being $5.0 \mu \mathrm{g} / \mathrm{larva}$.

\section{Materials and methods}

\section{Reagents}

Unless stated otherwise, all chemicals and reagents were sourced from Sigma Aldrich (Dorset UK) in their purest form listed. Green and blue fluorescent (latex) microspheres ranging from 0.5 to $6 \mu \mathrm{m}$ in diameter were purchased from Polysciences, Inc. (Fluoresbite ${ }^{\circledR}$ ). Stock solutions of indomethacin were prepared in 5\% dimethyl sulfoxide (DMSO; v/v) and diluted in filter-sterilized $(0.2 \mu \mathrm{m})$ phosphate-buffered saline (PBS) $\mathrm{pH}$ 7.4.

\section{Insects}

Larvae of G. mellonella (final instar) were purchased from Livefoods Direct Ltd (Sheffield UK). Upon arrival, each larva was inspected for signs of damage, infection and melanisation. Healthy larvae weighing between $0.25 \mathrm{~g}$ and $0.35 \mathrm{~g}$ were retained and stored at $15{ }^{\circ} \mathrm{C}$ in the dark for no more than 7 days.

\section{Larval survival and pupation studies}

Larvae were assigned randomly to each treatment $(n=10$ per replicate) and placed in $90 \mathrm{~mm}$ petri dishes lined with Whatman filter paper and wood shavings from the commercial supplier. Indomethacin was administered by intrahaemocoelic injection (INJ) or force feeding (FF; gavage) using a sterile 27 -gauge hypodermic needle across the concentration range, 0 to $7.5 \mu \mathrm{g} / \mathrm{larva}$. The volume of each inoculum was standardised to $10 \mu \mathrm{L}$. The negative control consisted of PBS pH 7.4 containing 5\% dimethyl sulfoxide (DMSO). Post-inoculation, larvae were incubated at $30{ }^{\circ} \mathrm{C}$ and assessed for mortality (response to prodding) and development (pupation events) for up to 10 days.

\section{Haemocyte counts and viability}

Larvae treated with indomethacin, PBS (containing 5\% DMSO), or untreated (i.e., no inoculation) were assessed for haemocyte numbers within 4- and 72-hours post-inoculation. Insects were chilled on ice for $\sim 3 \mathrm{~min}$ prior to injection of $100 \mu \mathrm{L}$ anticoagulant $(15 \mathrm{mM} \mathrm{NaCl}, 155 \mathrm{mM}$ trisodium citrate, $30 \mathrm{mM}$ citric acid, $20 \mathrm{mM}$ disodium EDTA, pH 5.5). Larvae containing anti-coagulant were placed back on ice for 2 min prior to piercing the integument above the head using a 27 -gauge hypodermic needle. Haemolymph was collected into pre-chilled, sterile microcentrifuge tubes. For haemocyte viability, haemolymph was extracted in the absence of anticoagulant and mixed in a ratio of $1: 5$ with $0.4 \%$ trypan blue (w/v in PBS) and incubated at room temperature for 1 to $2 \mathrm{~min}$. In all cases, haemolymph samples were applied to an improved Neubauer haemocytometer for cell enumeration using brightfield optics of a compound microscope. Two technical replicates were performed per sample. Haemocytes were considered dead when the cytoplasm stained positively for trypan-blue (Strober 2015). 


\section{Detoxification-associated assays}

Haemolymph was extracted (as stated above) and pooled from three larvae at 4, 24, 48 and $72 \mathrm{~h}$ after being forcefed indomethacin. Haemolymph was centrifuged at $500 \times g$ for $5 \mathrm{~min}$ at $4{ }^{\circ} \mathrm{C}$ to pellet the haemocytes. Approximately, $2.5 \times 10^{5}$ haemocytes from each treatment/time point were added to the lysis buffer $(50 \mathrm{mM}$ potassium phosphate, $2 \mathrm{mM}$ EDTA, $1 \mathrm{mM}$ DTT and a proteinase inhibitor cocktail (Roche cOmplete ${ }^{\mathrm{TM}}$ Mini kit)) and centrifuged at $14,000 \times g$ for $10 \mathrm{~min}$ at $4{ }^{\circ} \mathrm{C}$. Supernatants were retained and stored at $-80^{\circ} \mathrm{C}$. Midgut tissues from three larvae per treatment/time point were dissected out and washed in PBS. Approximately, $30 \mathrm{mg}$ of tissue was placed in $1 \mathrm{ml}$ lysis buffer and homogenised for $\sim 1$ min (using a borosilicate mini glass homogeniser) prior to centrifugation and storage as described above. Protein concentrations of haemolymph and midgut samples were determined using the Biuret method with bovine serum albumin (BSA, $0-20 \mathrm{mg} / \mathrm{ml}$ ) as a standard (Gornall et al. 1949).

\section{Superoxide dismutase (SOD) activity}

SOD activity (EC 1.15.1.1) was determined using the method described by Dubovskiy et al. (2008). Briefly, $80 \mu \mathrm{L}$ of sample (haemolymph or homogenised midgut) was mixed with reaction solution (500 $\mu \mathrm{L}$ PBS containing $70 \mu \mathrm{M}$ NBT, $125 \mu \mathrm{M}$ xanthine), followed by the addition of $20 \mu \mathrm{L}$ xanthine oxidase solution (5 mg BSA, $15 \mu \mathrm{L}$ xanthine oxidase (20 units/mL) per $\mathrm{ml}$ PBS), and incubated for $20 \mathrm{~min}$ at $28{ }^{\circ} \mathrm{C}$. Total assay volume was $600 \mu \mathrm{L}$. Xanthine oxidase catalyses xanthine to produce superoxide anions $\left(\mathrm{O}_{2}^{-}\right)$, which reduce NBT to a formazan dye. The inhibition of NBT reduction is indicative of SOD activity, which is monitored spectrophotometrically at $560 \mathrm{~nm}$. SOD activity is presented as the increase in absorbance $(560 \mathrm{~nm})$ per min per $\mathrm{mg}$ protein.

\section{Glutathione S-transferase (GST) activity}

GST activity (EC 2.5.1.18) was determined using the method described by Dubovskiy et al. (2008). Briefly, $20 \mu \mathrm{L}$ of sample was mixed with $500 \mu \mathrm{L}$ GST assay solution (1 mM glutathione, $1 \mathrm{mM}$ 1-chloro-2,4-dinitrobenzene (DNCB) dissolved in PBS) and incubated at $28^{\circ} \mathrm{C}$ for $5 \mathrm{~min}$. The reaction of DNCB and glutathione is catalysed by GST, producing 5-(2,4-dinitrophenyl)-glutathionedetectable at $340 \mathrm{~nm}$. GST activity is presented as the increase in absorbance $(340 \mathrm{~nm})$ per min per $\mathrm{mg}$ protein.

\section{Gut permeability assessments}

Fluorescently tagged, carboxylate-modified latex microspheres $\left(1 \times 10^{6}\right)$ of $0.5 \mu \mathrm{m}, 1 \mu \mathrm{m}, 2 \mu \mathrm{m}$ and $6 \mu \mathrm{m}$ in diameter were resuspended in $10 \mu \mathrm{L}$ PBS (control) or $10 \mu \mathrm{L}$ indomethacin solution ( 1 or $7.5 \mu \mathrm{g}$ dose) to form co-inoculates (thereby avoiding piercing an insect twice). Larvae were force-fed $10 \mu \mathrm{L}$ of each co-inoculate and incubated at $30{ }^{\circ} \mathrm{C}$ until haemolymph and faeces were collected from each treatment group at 4, 24, 48 and $72 \mathrm{~h}$. Faeces were homogenised in $1 \mathrm{~mL}$ PBS pH 7.4. The number of microspheres in the haemolymph/faeces was enumerated using a fluorescent microscope (Olympus Bx43f).

\section{Histopathology of the insect alimentary canal}

Larvae force-fed indomethacin (7.5 $\mu \mathrm{g}$ per insect) or PBS (negative control) were killed at 4, 24, 48 and $72 \mathrm{~h}$ postinoculation by intrahaemocoelic injection of $100 \mu \mathrm{L} 10 \%$ buffered formalin, immediately prior to submersion in the same solution for $24 \mathrm{~h}$. Larvae were cut into three sections, head, middle and posterior (anus), and stored in 70\% ethanol prior to wax embedding. Briefly, each sample was dehydrated using an ethanol series, $70 \%, 80 \%$ and $90 \%$ for $1 \mathrm{~h}$ each, followed by $3 \times 1$ h 100\% ethanol washes. Dehydrated samples were washed twice in HistoClear or HistoChoice (Sigma Aldrich) for $1 \mathrm{~h}$ each to remove any remaining residues. Samples were resuspended in 50:50 HistoChoice: paraffin wax for $1 \mathrm{~h}$ prior to complete wax embedding. Embedded samples were cut into $\sim 6 \mu \mathrm{m}$ sections using a microtome, adhered to glass slides with egg albumin solution $(\sim 1 \% \mathrm{w} / \mathrm{v})$ and dried for $24 \mathrm{~h}$ before staining. Loaded slides were stained using Cole's haematoxylin and eosin (see Supp. Materials for further details).

\section{X-ray microtomography/microscopy of Galleria mellonella}

Larvae force-fed PBS were killed at $72 \mathrm{~h}$ and fixed with $10 \%$ formalin for $30 \mathrm{~h}$, followed by dehydration in $100 \%$ ethanol for $24 \mathrm{~h}$. Samples were submerged in Lugol's iodine (PRO.LAB Diagnostics) for 2 weeks and washed with $70 \%$ ethanol prior to microscopy. Insect samples were analysed via X-ray microscopy (XRM) using a lab-based Zeiss Xradia 520 (Carl Zeiss XRM, Pleasanton, CA, USA) $\mathrm{X}$-ray microscope attached to a CCD detector system with scintillator-coupled visible light optics, and tungsten transmission target. The specimen was placed in a plastic screw-top microcentrifuge tube and submerged in $75 \%$ ethanol to prevent the tissues from drying out. To achieve a higher resolution over the entire organism, the insect was imaged along its $\sim 25 \mathrm{~mm}$ length at high resolution, using an overlap-scan and stitching procedure including five 
individual scans, with $44 \%$ overlap between each scan. An $\mathrm{X}$-ray tube voltage of $80 \mathrm{kV}$ and a tube current of $87 \mu \mathrm{A}$ were used with an exposure of $1000 \mathrm{~ms}$ and a total of 3201 projections. An objective lens giving an optical magnification of 0.4 was selected with binning set to 2 , producing an isotropic voxel (3-D pixel) size of $8.5635 \mu \mathrm{m}$. The individual tomograms were reconstructed from 2-D projections and stitched into a single large volume using a Zeiss commercial software package (XMReconstructor, Carl Zeiss), utilising a cone-beam reconstruction algorithm based on filtered back-projection. XMReconstructor was also used to produce 2-D grey scale slices for subsequent analysis. Drishti and Drishti Paint software V2.6.4. (Limaye 2012) was employed to highlight regions of interest and digitally segment the alimentary canal.

\section{Data handling}

All data were gathered from experiments carried out on at least three independent occasions and are represented by mean values \pm standard error (see individual figure legends for sample sizes). D'Agostino and Pearson normality tests were performed, and if necessary, data were squareroot transformed. Results from survival studies were analysed using the log-rank (Mantel-Cox) test for comparing curves, whereas larval pupation levels, total haemocyte counts, cell deaths, and faecal/haemolymph microsphere loads were analysed using 2- or 3-way ANOVA with Tukey's multiple comparison tests in GraphPad Prism v7. A Pearson's Correlation test was employed to assess the relationship between microsphere size $(0.5-6 \mu \mathrm{m})$ and their presence in the haemolymph of control larvae. Enzyme assays, GST and SOD, were analysed in ' $R$ ' studio using General Liner Hypotheses (ghlt). In all cases, differences were considered significant when $P \leq 0.05$.

Histology slides were single-blind assessed using paired treatment $(n=13)$ and control $(n=13)$ samples from 4 to $72 \mathrm{~h}$. A grading system (1-4) was used to categorise the extent of tissue damage(s) or lack thereof (see Supp. Materials for descriptions). Drishti and Drishti Paint V2.6.4. (Limaye 2012) and ImageJ (Abràmoff et al. 2004) software were used to process/present microscopy findings. Images were adjusted for colour balance and contrast/brightness only.

\section{Results}

\section{Evaluating the relative toxicity of indomethacin on Galleria mellonella}

\section{Survival}

Intrahaemocoelic injection of indomethacin had no measurable negative impacts on larval survival across the concentration range $0.5-7.5 \mu \mathrm{g} /$ larva ( $0 \%$ mortality), which is the equivalent to $2-30 \mathrm{mg} / \mathrm{kg}$ in rodents. Oral administration of indomethacin (force-feeding) in excess of $2.5 \mu \mathrm{g} / \mathrm{larva}$ led to a $7-10 \%$ decline in survival within $72 \mathrm{~h}$ (Fig. 1) but was not found to be statistically significant overall (log-rank (Mantel-Cox) test; $\left.X^{2}(6)=11.71, P=0.0688\right)$. Further inspection of the survival curves revealed no statistical differences between the PBS/DMSO controls and either $2.5 \mu \mathrm{g} /$ larva $\left(X^{2}(1)=2.034, P=0.1538\right)$ or $5-7.5 \mu \mathrm{g} / \mathrm{larva}\left(X^{2}(1)=3.105\right.$, $P=0.0780)$.

\section{Development}

Approximately $87 \%$ of untreated larvae transitioned into pupae after 6 days incubation at $30^{\circ} \mathrm{C}$ (experimental temperature)-increasing to $97 \%$ by day 10 (Fig. 2). No more than $40 \%$ of G. mellonella force-fed indomethacin $(0.5-7.5 \mu \mathrm{g} /$

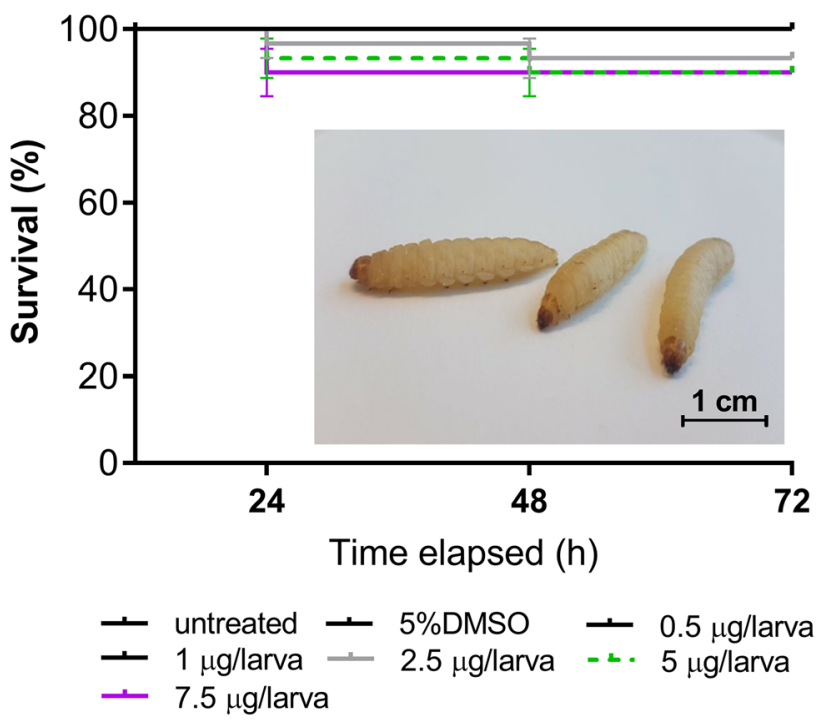

Fig. 1 Survival of Galleria mellonella larvae following force-feeding (gavage) of indomethacin, 0.5-7.5 $\mu \mathrm{g} / \mathrm{larva}$. Post-inoculation, larvae were maintained in darkness at $30^{\circ} \mathrm{C}$ for $72 \mathrm{~h}$. Larvae that were unresponsive to being rolled over or prodded were considered dead. Values are expressed as mean \pm SE $(n=30$ per treatment, 210 in total). Inset: three healthy (untreated) G. mellonella larvae. It should be noted that direct injection of indomethacin or PBS with 5\% DMSO (control) did not lead to any insect mortality 

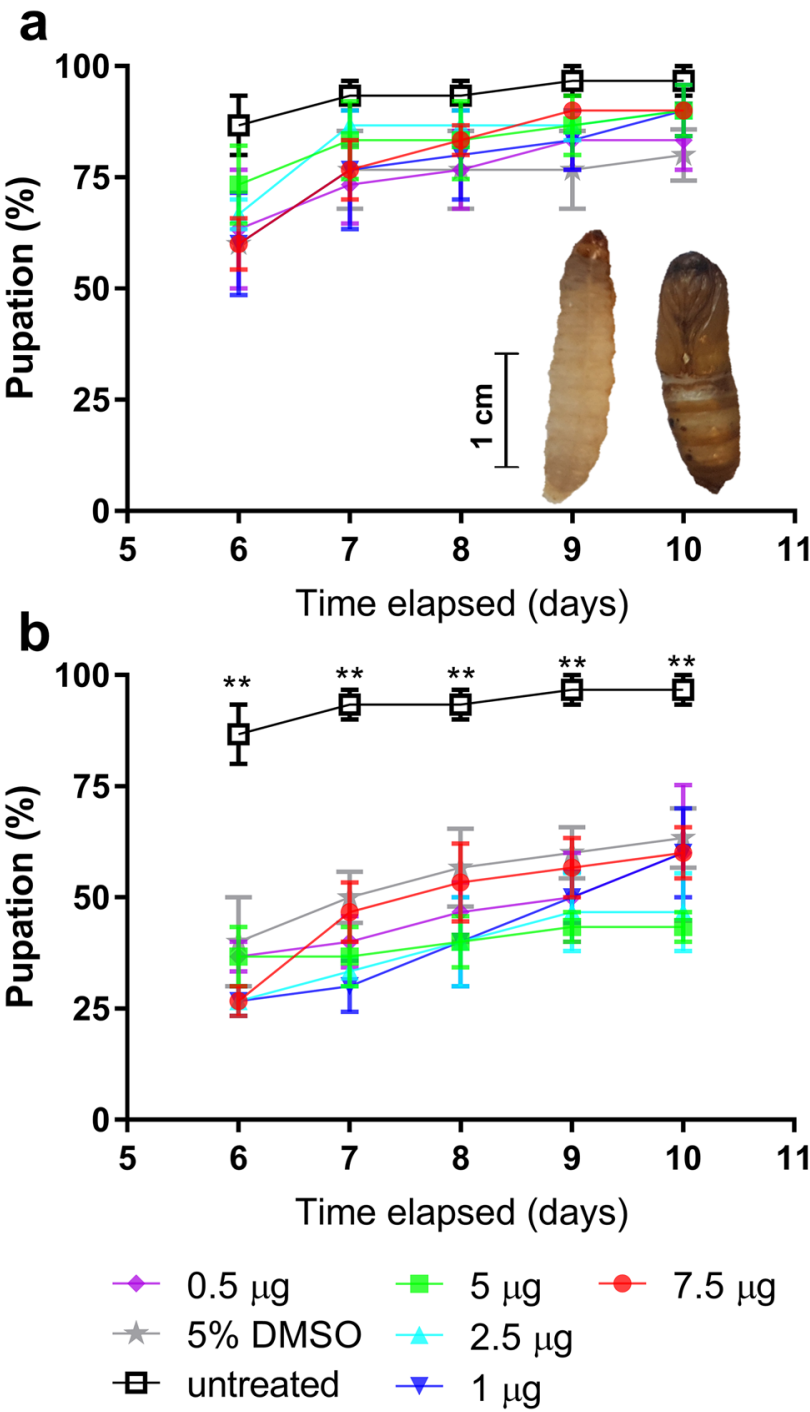

Fig. 2 Development (pupation) of Galleria mellonella larvae following inoculation with indomethacin, 0.5-7.5 $\mu \mathrm{g} / \mathrm{larva}$. Larvae received indomethacin via intrahaemocoelic injection (a) or force feeding (b) and were maintained subsequently in darkness at $30{ }^{\circ} \mathrm{C}$ for 10 days. The number of larvae undergoing pupation was recorded. Inset (a): typical appearances of a healthy larva (left image) and a moth pupa (right image). Values are expressed as mean \pm SE ( $n=30$ per treatment, 390 in total across both inoculation methods). Symbol: ** $P<0.01$ when comparing untreated to all other treatments at the respective time points. The negative control consisted of force feeding or injecting the insect with PBS containing 5\% DMSO

larva) or PBS ( $+5 \%$ DMSO, absent indomethacin) were observed pupating at day 6 . By day 10 , numbers of pupae increased to $80-90 \%$ for injected larvae (Fig. 2a) and $\leq 63 \%$ for force-fed larvae (Fig. 2b). Using a three-way ANOVA, we determined time (Days 6 and 10) and inoculation method (FF and INJ) to account for $38 \%(F(1,24)=50.02$, $P<0.0001)$ and $41 \%(F(1,24)=54.19, P<0.0001)$ of the variation, respectively. Less than $0.5 \%$ of the variation within the data can be attributed to treatment: PBS + 5\% DMSO (negative control), $1 \mu \mathrm{g}$ (low dose) and $7.5 \mu \mathrm{g}$ (high dose) indomethacin per larva $(F(2,24)=0.0833, P=0.92)$. Tukey's multiple comparison (post hoc) tests revealed statistical differences between the untreated insects and those force-fed indomethacin or PBS only (Fig. 2b), with no differences detected between mean values of injected insects at any time-point. These data suggest the route of administration alone can delay the onset of pupation, and it is unlikely due to indomethacin exposure.

\section{Circulating blood cells (haemocytes)}

To investigate further any potential non-target effects of indomethacin, we monitored immune cell (haemocyte) numbers and levels of cell death within the insect haemolymph (i.e., blood). Total haemocyte counts varied little in untreated and PBS ( $+5 \%$ DMSO) control insects over the 72-h experimental period, $2.5-3 \times 10^{6} / \mathrm{mL}$ and $2.7-3.7 \times 10^{6} \%$ $\mathrm{mL}$, respectively (Fig. 3). At $24 \mathrm{~h}$ post-inoculation, all concentrations of indomethacin injected into the haemolymph led to substantial increases in haemocyte numbers (up to $\left.5 \times 10^{6} / \mathrm{mL}\right)$ compared to the untreated/control $\left(<2.8 \times 10^{6} /\right.$ $\mathrm{mL}$; Fig. 3a). Force-feeding indomethacin led to increased circulating haemocyte numbers at the highest dose of $7.5 \mu \mathrm{g} /$ larva only $\left(4.4 \times 10^{6} / \mathrm{mL}\right.$; Fig. $\left.3 b\right)$. In all cases, haemocyte numbers returned to control levels by $48 \mathrm{~h}$. A 2-way ANOVA revealed treatment to account for $15-19 \%$ of the variation within the data $(\mathrm{INJ}-F(4,40)=4.488, P=0.0043$; $\mathrm{FF}-F(4,40)=2.988, P=0.030)$. Time accounted for $<5 \%$ of the variation in force-fed insects (Time, $F(3,40)=1.033$, $P=0.3884$ ) but $\sim 30 \%$ for injected insects (Time, $F(3$, $40)=11.84, P<0.0001)$. These data likely reflect the unimpeded exposure of haemocytes to indomethacin when it is administered directly into the haemocoel (body cavity), whereas the gut presents a natural barrier when administered via force-feeding.

Concerning cytotoxicity, proportions of haemocytes staining positively for trypan-blue (i.e., dead or dying) ranged from 7 to $12 \%$ for the duration of the experimentregardless of the inoculation method used or dose of indomethacin (Fig. 3; Supp. Table 1).

\section{Characterising the effects of indomethacin on the midgut of Galleria mellonella}

\section{Alimentary canal mapping}

Using X-ray microtomography, we mapped the alimentary canal and integumentary musculature of $G$. mellonella larvae $(n=3)$ over their entire $\sim 25 \mathrm{~mm}$ lengths with a resolution of $8.6 \mu \mathrm{m}$ (Fig. $4 \mathrm{a}-\mathrm{c}$ ). Like most insects, the alimentary canal can be sub-categorised into three regions: foregut, midgut and hindgut (Fig. 4b). The midgut is 

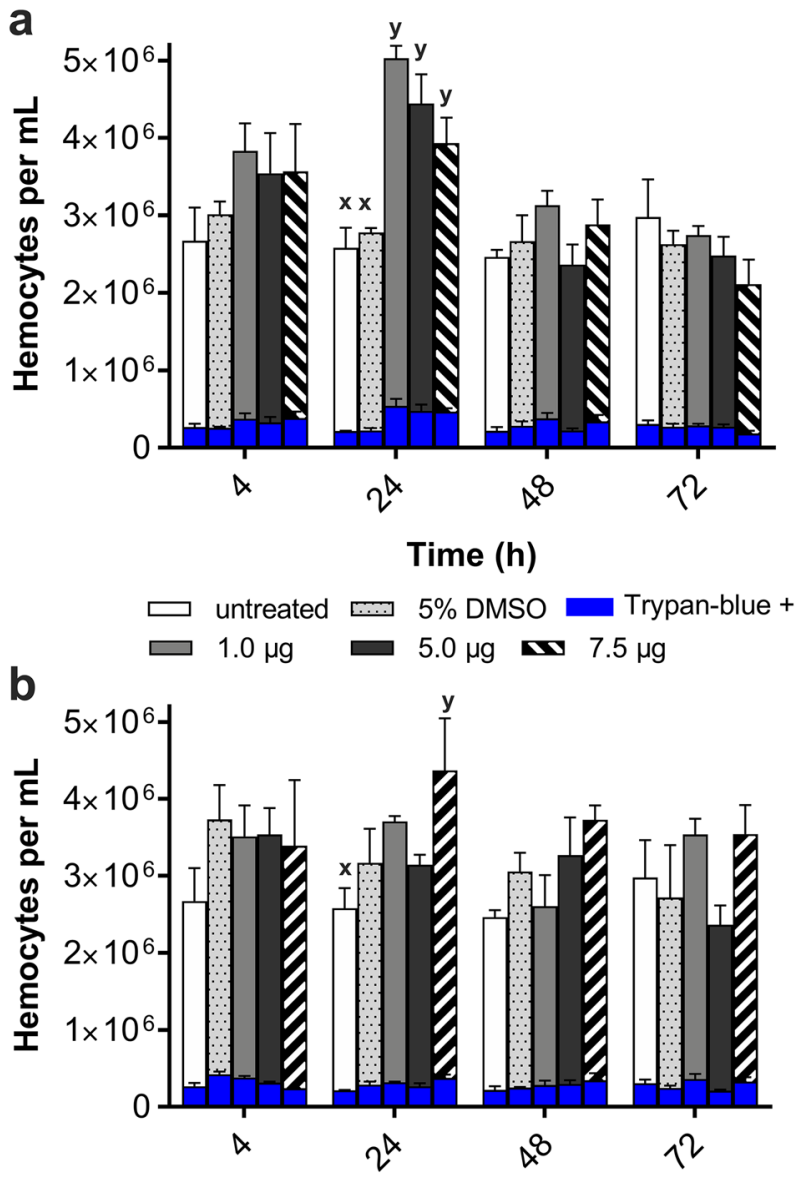

Time (h)

Fig. 3 Haemocyte responses of Galleria mellonella larvae following inoculation of indomethacin, 1-7.5 $\mu \mathrm{g} / \mathrm{larva}$. Larvae received indomethacin via intrahaemocoelic injection (a) or force feeding (b) and were maintained subsequently in darkness at $30{ }^{\circ} \mathrm{C}$ for 3 days. Total haemocyte counts were performed, and haemocyte viability was determined using the trypan blue exclusion assay (dead cell numbers are represented by the blue bars in $\mathbf{a}$ and $\mathbf{b}$ ). Values are presented as the mean \pm SE ( $n=36$ per treatment, 324 in total across both inoculation methods). Unshared letters (x, y) represent significant differences $(P \leq 0.05)$ determined by Tukey's multiple comparison tests. The negative control consisted of force feeding or injecting the insect with PBS containing 5\% DMSO (colour figure online)

distinguishable from the fore- and hind-guts due to the absence of a cuticle lining, and our measurements indicate that the midgut tissues make-up $>50 \%$ of the alimentary canal $(n=3)$ in this species. The midgut is arranged into pleats or folds of columnar epithelial cells and goblet cells that produce and maintain the peritrophic matrix (functional equivalent to the human mucus layer). Visceral (striated) muscles surround the gut tissues (anchoring the cellular arrangements in place) and represent the final layer between the gut contents and the haemolymph.

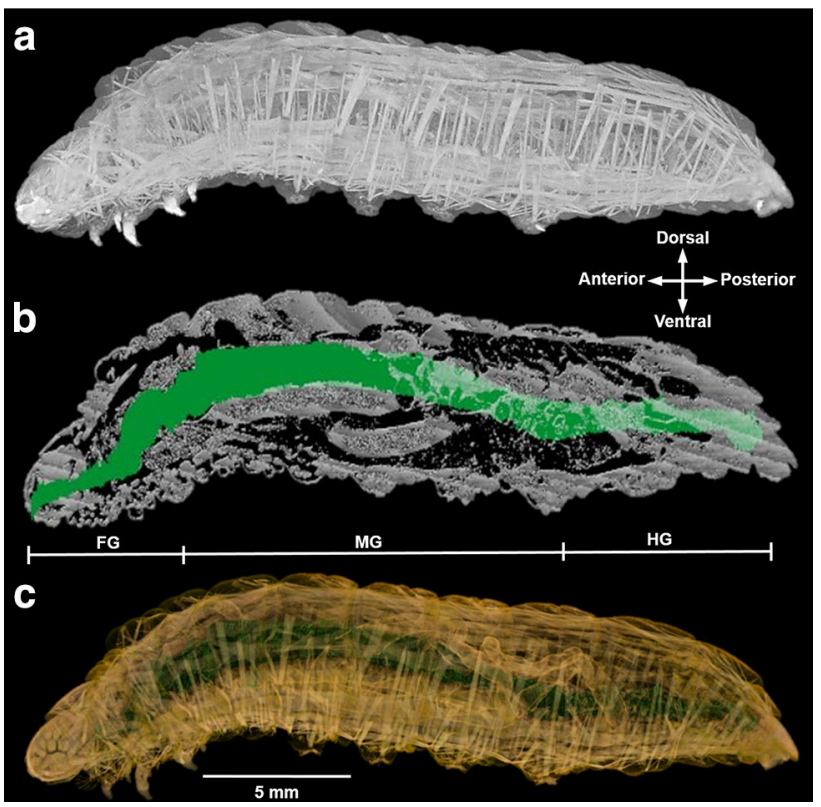

Fig. 4 X-ray microtomography of Galleria mellonella. a 3-dimensional render of a representative insect larva stained with Lugol's iodine. Striated muscle fibres are distributed throughout the insectmuscles are attached to the integument and run through the cuticle layers. b The entire alimentary canal of the insect larva was highlighted by manually inspecting and colouring 1014 slices using Drishti software (Limaye 2012). FG, foregut; MG, midgut; HD, hindgut. c Combined 3-dimensional render with the integument architecture coloured yellow and the alimentary canal coloured green

\section{Gut permeability}

Indomethacin and NSAIDs broadly increase gastrointestinal 'leakiness' in humans and rodents, with tissue damage located in the small intestine and colon (Smecuol et al. 2001). In order to test whether indomethacin caused similar pathological symptoms in the insect alimentary canal, we force-fed G. mellonella inocula containing indomethacin (0, 1 or $7.5 \mu \mathrm{g} / \mathrm{larva}$ ) and a selection of microspheres, $0.5-6 \mu \mathrm{m}$ in diameter (Fig. 5). In the absence of indomethacin (PBS [+5\%DMSO] only), the majority of $6 \mu \mathrm{m}$ and $2 \mu \mathrm{m}$ spheres (36-58\%) made their way down the alimentary canal and were defecated within $24 \mathrm{~h}$ (Fig. 5a, b), whereas $1 \mu \mathrm{m}$ spheres (33\%) were released later at $48 \mathrm{~h}$ (Fig. $5 \mathrm{c}$ ). The presence of indomethacin ( 1 or $7.5 \mu \mathrm{g} / \mathrm{larva}$ ) led to substantial increases in the number of microspheres $(0.5-6 \mu \mathrm{m})$ detected in the haemolymph (blood) and concomitantly fewer were recovered from faeces. At 4 and $24 \mathrm{~h}$ post-indomethacin treatment, $2.7-3.1 \times 10^{4}(6 \mu \mathrm{m})$ spheres leaked from the gut into the haemolymph in comparison to the control, $1.0-1.4 \times 10^{4}$ (Fig. 5a). Notably, the presence of microspheres in the haemolymph was recognised by phagocytic haemocytes and subsequently internalised (Supp. Figure 1). Independent of microsphere size, indomethacin exacerbated 
Fig. 5 Gut permeability of Galleria mellonella larvae following force feeding of indomethacin, 0-7.5 $\mu \mathrm{g} / \mathrm{larva}$. Permeability (or leakiness) was determined by the number of $6 \mu \mathrm{m}$ (a), $2 \mu \mathrm{m}$ (b), $1 \mu \mathrm{m}$ (c) and $0.5 \mu \mathrm{m}$ (d) spheres found in the haemolymph and faeces between 4 and $72 \mathrm{~h}$ post-inoculation. Each larva was co-inoculated with $1 \times 10^{6}$ microspheres and indomethacin $(1,7.5 \mu \mathrm{g} / \mathrm{larva})$ or PBS and incubated in the dark at $30^{\circ} \mathrm{C}$. Data represent the mean $\pm \mathrm{SE}$ $(n=36,432$ in total across all four microsphere sizes). Symbol: $* P<0.05$ when comparing PBS to indomethacin treatments at each respective time point. Unshared letters $(\mathrm{a}, \mathrm{b})$ represent significant differences $(P<0.05)$ determined by Tukey's multiple comparison tests. The negative control consisted of force feeding the insect with PBS ( $+5 \%$ DMSO) in the absence of indomethacin $(0 \mu \mathrm{g} / \mathrm{larva})$

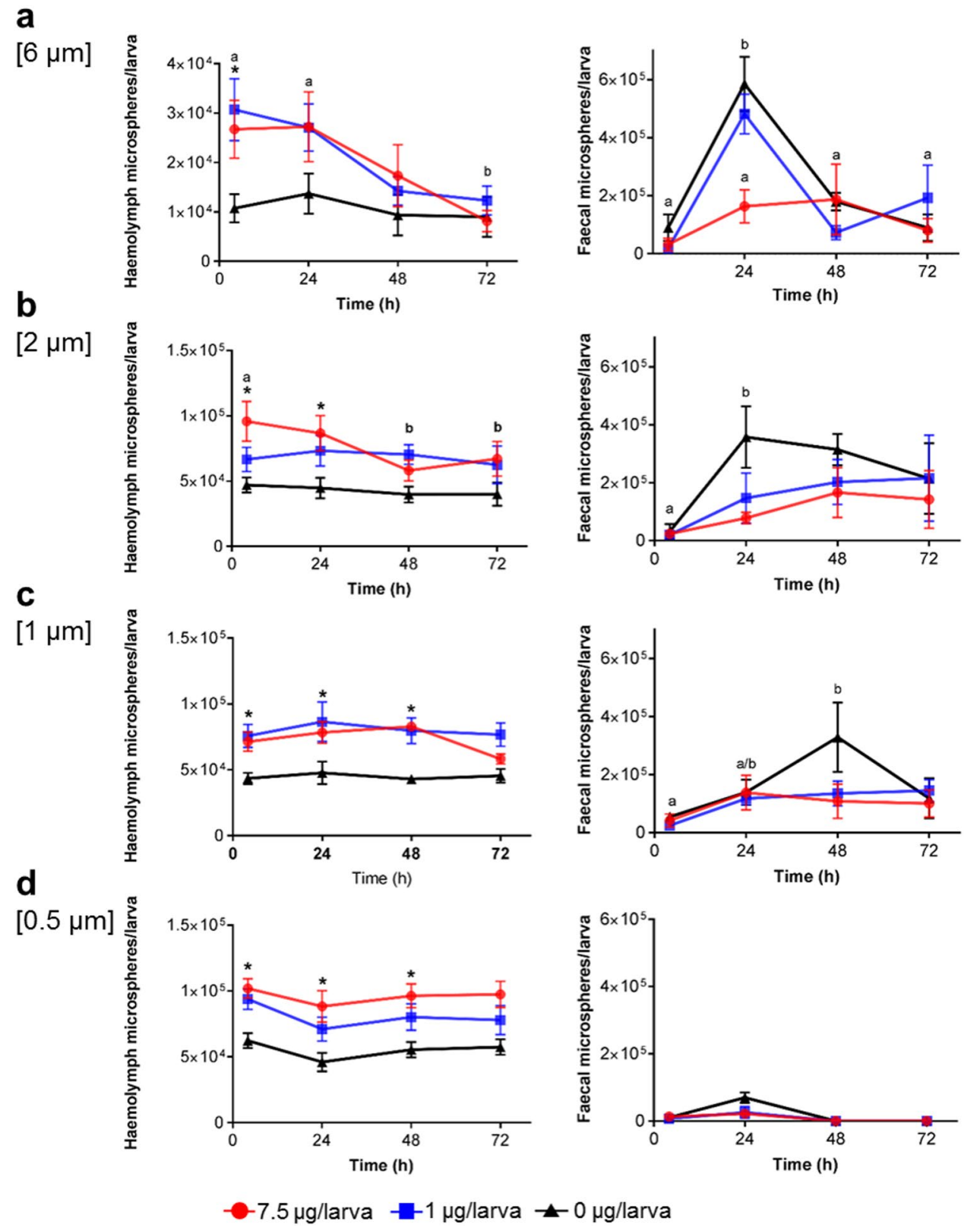

gut leakiness by 1.4- to 3-fold: $6 \mu \mathrm{m}(F(2,24)=5.801$, $P=0.0042), 2 \mu \mathrm{m}(F(2,24)=11.04, P<0.0001), 1 \mu \mathrm{m}$ $(F(2,24)=21.48, P<0.0001)$, and $0.5 \mu \mathrm{m}(F(2,24)=22.75$, $P<0.0001)$ and accounted for $9-30 \%$ of the variation in haemolymph loads. In contrast, time accounted for the majority of variation, $25-51 \%$, in faecal microsphere loads: $6 \mu \mathrm{m}(F(3,24)=17.38, P<0.0001), 2 \mu \mathrm{m}(F(3,24)=3.57$, $P=0.0288), 1 \mu \mathrm{m}(F(3,24)=3.94, P=0.0204)$, and $0.5 \mu \mathrm{m}$ $(F(3,24)=8.378, P=0.0006)$.

Overall, significantly fewer $0.5 \mu \mathrm{m}$ spheres made their way into the faeces within $24 \mathrm{~h}$ and beyond (Fig. 5d). This is likely due to the small size enabling movement across the gut barrier, and, those that remain within the midgut may get caught-up in tissue folds (Supp. Figure 2), thereby delaying passage through the hindgut/rectum. By analysing the control data (absent indomethacin) across the 72-h period (Supp. Figure 3), we found a strong inverse correlation between microsphere size and haemolymph loads (Pearson Correlation; $r=-0.988, P=0.0115, R^{2}=9.771$ ) in support of our theory.

\section{Gastric damage of the midgut}

We further examined the effects of force-feeding indomethacin $(7.5 \mu \mathrm{g} / \mathrm{larva})$ and PBS (+5\%DMSO) on G. mellonella larvae using wax (H\&E) histology. The larval midgut in the presence of PBS did not show any clear symptoms of damage or altered tissue morphology (Fig. 6-upper panels). 
Fig. 6 Gross histopathology of the midgut tissues from control and indomethacin-treated Galleria mellonella. Photomicrographs depict transverse sections of the midgut architecture at 4, 24, 48 and $72 \mathrm{~h}$ after force-feeding PBS (controlupper panels) or indomethacin (7.5 $\mu \mathrm{g}$-lower panels). Black boxes (broken lines) are used to highlight magnified regions of interest. Ap, apical; Ba, basolateral; $\mathrm{BB}$, brush border; $\mathrm{BC}$, body cavity; bl, blebbing/ blistering of the cells; BM, basement membrane; c, columnar epithelial cell; g, goblet cell Lu, lumen; M, muscle; v, vacuole. An asterisk (*) denotes cellular damage and displacement into the lumen, and black arrows point to haemocytes (immune cells) within the body cavity (haemocoel). The negative control consisted of force feeding the insect with PBS (+5\% DMSO) in the absence of indomethacin $(0 \mu \mathrm{g} /$ larva $)$

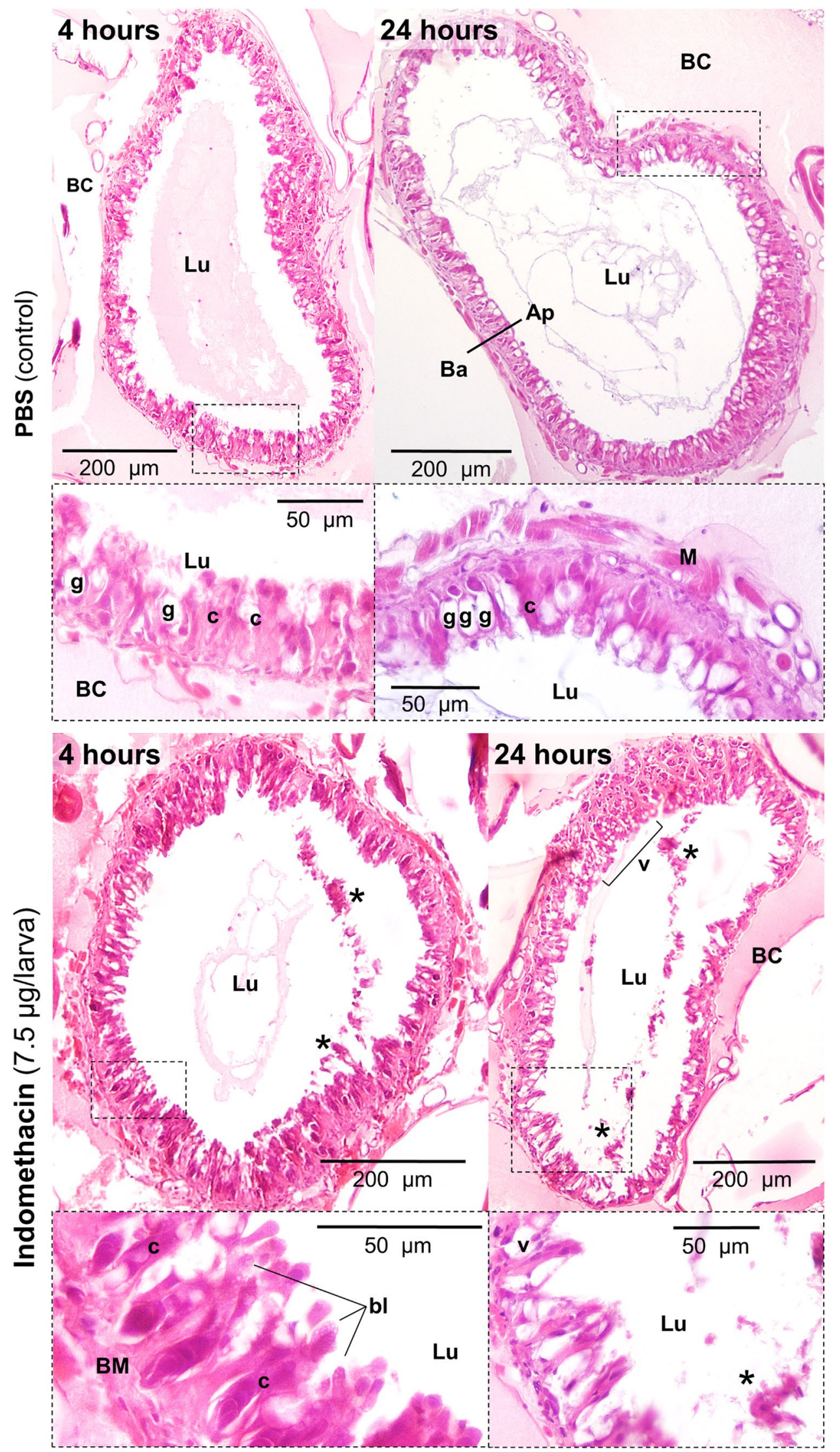


Fig. 6 (continued)
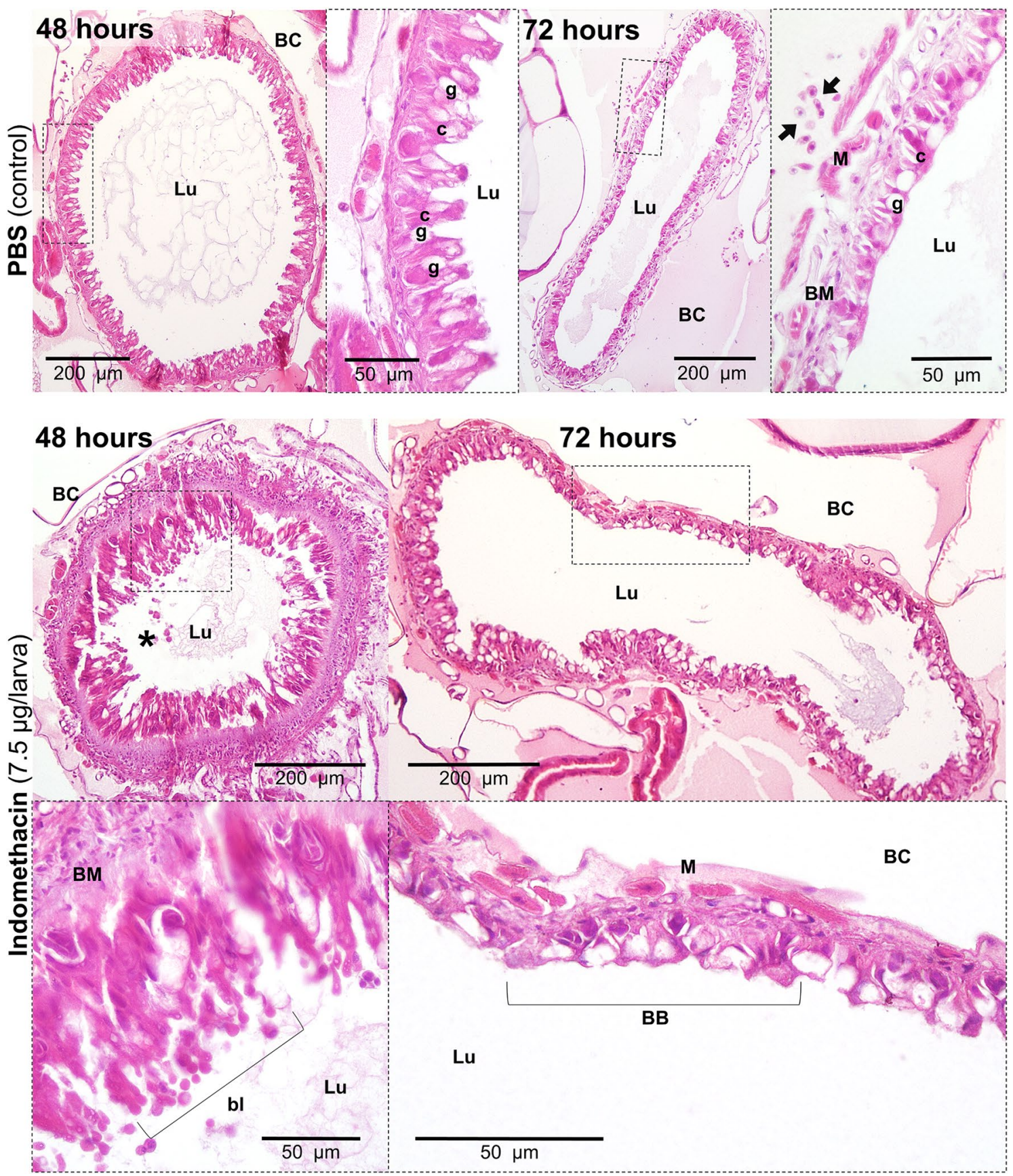

Uniform cellular arrangements of epithelial and goblet cells were observed, in addition to an intact basement membrane and visceral (striated) muscle layer. All control slides were considered grade 1 (0-2 discrete changes), with the exception of a single section at the 48-h time point that was assigned grade 2 (Supp. Figure 4). Following indomethacin treatment, varying levels of tissue damage and midgut degradation were visible within $4-48 \mathrm{~h}$ of all insects surveyed (Fig. 6-lower panels). Tissue slides were assigned damage grades 2 to 4 at $4 \mathrm{~h}$, and grades $2 / 3$ at 24 and $48 \mathrm{~h}$ (Supp.
Figure 4) - representing at least five aberrations per slide (discrete, localised changes) to $>50 \%$ compromised tissue (global damage; Fig. 7). Deterioration of the larval gut manifested as sloughed epithelial cells, increased vacuolisation, partial/complete displacement of the gut lining into the lumen, cellular debris (or potential apoptotic bodies), membrane blistering/blebbing, nuclear condensation (pyknosis) and fragmentation (karyhorrhexis) (Figs. 6, 7). By $72 \mathrm{~h}$, the majority of slides were graded 1 and 2 (Supp. Figure 4), which suggests the tissue is being repaired. 


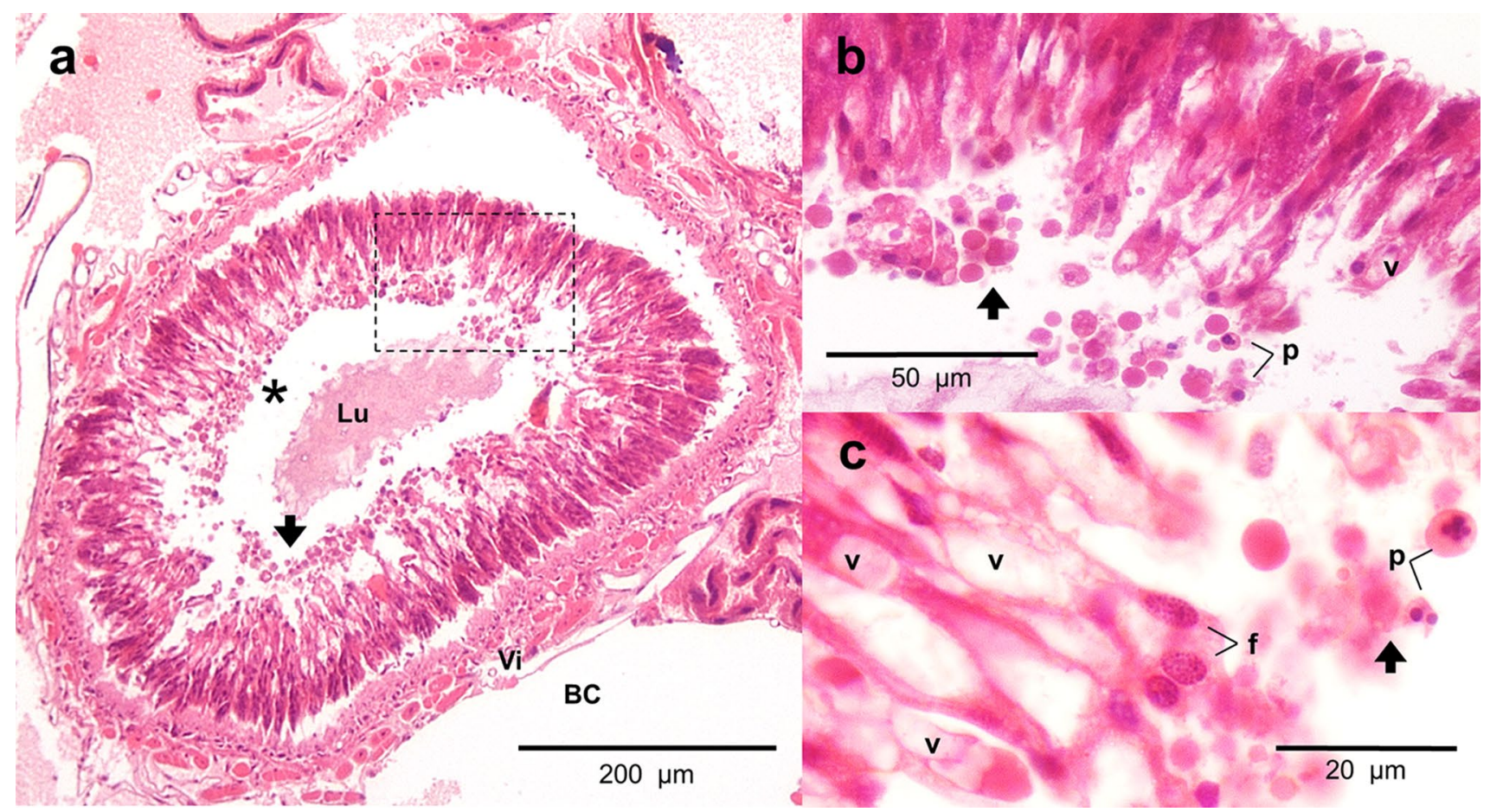

Fig. 7 Histopathology of compromised midgut tissues from Galleria mellonella force-fed $(7.5 \mu \mathrm{g})$ indomethacin. a Transverse section of the larval midgut at $4 \mathrm{~h}$ post-treatment. The photomicrograph displays severe global tissue damage, where almost the entire epithelium has dissociated (sloughed) from the basement membrane and visceral (Vi) muscle. The black arrows (all panels) signify the large number of

Fig. 8 Detoxification-associated activities within Galleria mellonella following forcefeeding of indomethacin, $0-7.5 \mu \mathrm{g} /$ larva. Glutathione $S$-transferase activity was determined in the midgut (a) and haemolymph (b) by the change in 5-(2,4-dinitrophenyl)glutathione accumulation (A340 nm). Superoxide dismutase activity was determined in the midgut (c) and haemolymph (d) via the inhibition of NBT reduction (A560 nm). Data are presented as floating bars (min, max) with mean lines shown $(n=36$ per treatment, 180 in total; 3 insects were pooled at each time point). Unshared letters $(\mathrm{a}, \mathrm{b})$ represent statistical differences $(P<0.05)$ as determined by Tukey's multiple comparison tests. The negative control consisted of force feeding the insects with PBS $+5 \%$ DMSO in the absence of indomethacin $(0 \mu \mathrm{g} / \mathrm{larva})$ a
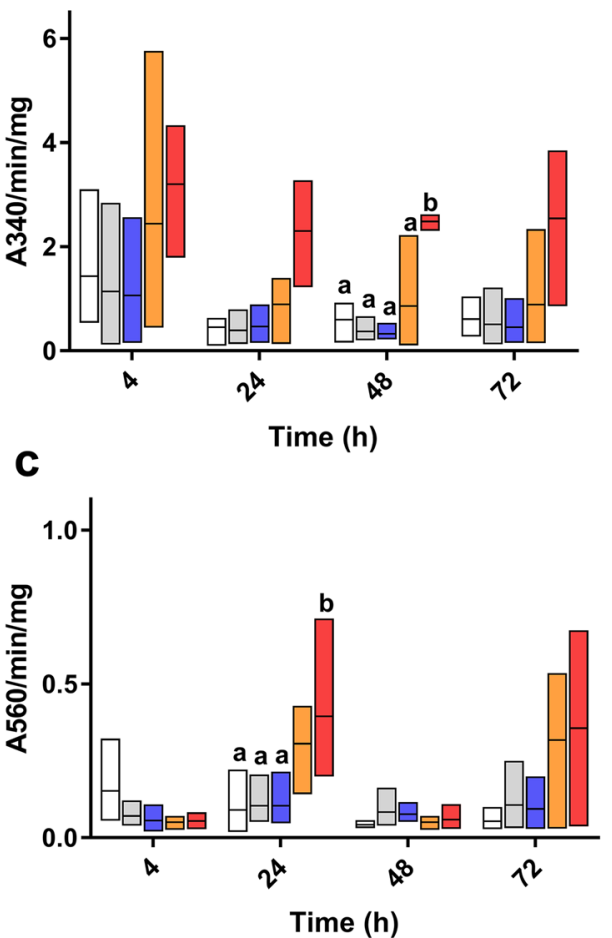

b
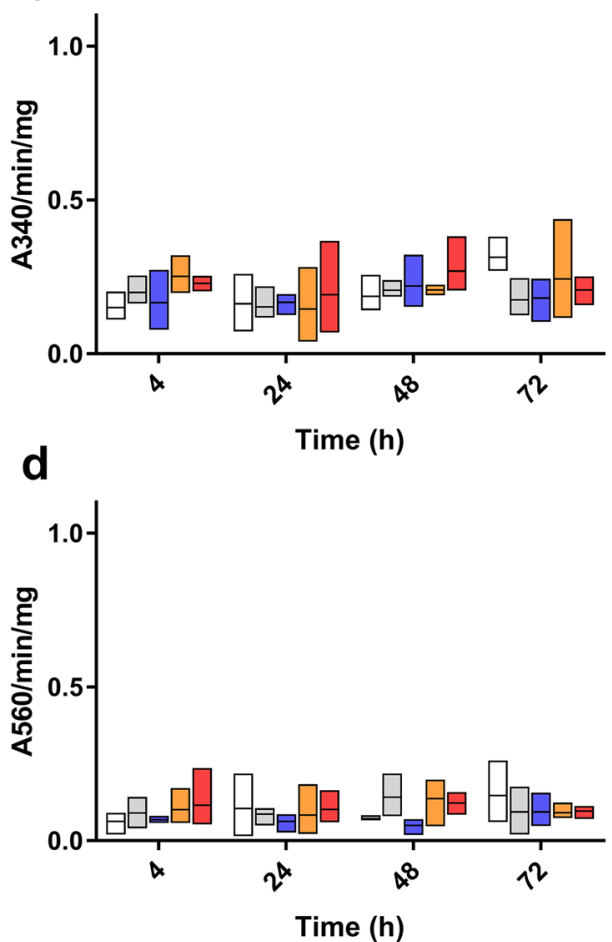

$\square$ untreated $\square 1 \mu \mathrm{g} /$ larva $\square 7.5 \mu \mathrm{g} /$ larva
$\square$ 5\% DMSO $\square$ ( 5 g/larva 


\section{Gut repair (detoxification)}

Administration of indomethacin by force feeding led to significant increases in glutathione- $S$-transferase $(F(4$, $40)=7.35, P=0.0002)$ and superoxide dismutase (F (4, $40)=2.635 P=0.0481)$ activities within the gut, but not in the haemolymph $(\mathrm{GST} ; F(4,40)=0.5449, P=0.704$ and SOD; $F(4,40)=0.801, P=0.515$; Fig. 8$)$. Larvae that were inoculated with $7.5 \mu \mathrm{g}$ indomethacin demonstrated consistently higher levels of GST activity in the gut, 2.3-3.2 Abs[340 nm] $/ \mathrm{min} / \mathrm{mg}$, when compared to all other treatments/controls and timepoints (Fig. 8a), whereas SOD activity peaked at 24 and $72 \mathrm{~h}, \sim 0.4 \mathrm{Abs}[560 \mathrm{~nm}] / \mathrm{min} / \mathrm{mg}$ (Fig. 8c). A two-way ANOVA revealed time to be a significant factor regarding SOD activity $(F(3,40)=4.266$, $P=0.0105)$, but this was not the case for GST $(F(3$, $40)=2.584, P=0.067)$. These patterns of enzyme activity complement the restored nature of the midgut tissues seen at $72 \mathrm{~h}$ in the histology (Fig. 6). Detoxification-associated activities in the haemolymph remained below 0.32 Abs[340 nm] $/ \mathrm{min} / \mathrm{mg}$ for GST and $0.15 \mathrm{Abs}[560 \mathrm{~nm}] /$ $\mathrm{min} / \mathrm{mg}$ for SOD (Fig. 8b, d) - indicating strongly that the adverse effects of indomethacin were restricted to the gut.

\section{Discussion}

We assessed the relative toxicity of indomethacin in insect larvae via gavage (force-feeding) and intrahaemocoelic injection across a concentration range relevant to rodent models, $2-30 \mathrm{mg} / \mathrm{kg}(0.5-7.5 \mu \mathrm{g} / \mathrm{larva})$, and found negligible side effects in terms of survival, development or immune cytotoxicity (Figs. 1, 2, 3). When force-fed, larvae displayed broad symptoms of injury to the alimentary canal (Figs. 5, $6,7,8)$, e.g., a threefold increase in gut permeability and tissue degradation. We present considerable evidence that the integrity of the midgut is compromised by indomethacin within 4 to $24 \mathrm{~h}$, causing sufficient damage to activate repair/detoxification mechanisms (GST and SOD). The onset of indomethacin-associated gut leakiness has also been recorded within $24 \mathrm{~h}$ in humans and mice, alongside ulceration and epithelial cell shrinkage (Playford et al. 1999, 2001; Bjarnason and Takeuchi 2009). Our combined use of X-ray microtomography and wax histology provides novel insight into the gross anatomy of the G. mellonella digestive tracthighlighting the suitability of the midgut for comparative pathobiology (Figs. 4, 5, 6, 7, Supp. Figure 2).

Indomethacin is a broad inhibitor of cyclooxygenase isozymes (COX1 and COX2), which are responsible for the initiation of prostaglandin synthesis $\left(\mathrm{PGG}_{2}\right)$, and ultimately, the maintenance of inflammatory programmes and gastrointestinal mucosa (reviewed by Brune and Patrignani 2015). In a previous study by Büyükgüzel et al. (2007), eicosanoid presence in the haemolymph was deemed essential for mediating nodule formation - a cellular defence reaction-during viremia. When they injected $50 \mu \mathrm{g}$ of indomethacin into the haemocoel, there was a significant reduction in the number of nodules formed. We did not notice a reduction in the phagocytic capacity of haemocytes in insects forcefed $7.5 \mu \mathrm{g}$ indomethacin and latex microspheres (Supp. Figure 1), which is also in contrast to earlier findings by Mandato et al. (1997). The authors reported on a reduction in the phagocytic index of G. mellonella haemocytes when exposed to $10 \mu \mathrm{M}$ indomethacin in vitro (Mandato et al. 1997). A likely explanation for this discrepancy is that the majority of force-fed indomethacin remains in the midgut of our insects, despite the microspheres leaking into the surrounding haemolymph (where they are targeted by haemocytes; Supp. Figure 1). The immune cells of insects, namely the haemocytes, share many mechanistic and structural similarities with the innate immune cells of vertebrates, including pathogen recognition receptor signalling and phagocytosis-associated respiratory burst (Renwick et al. 2007; Browne et al. 2013; Butt et al. 2016). Mandato et al. (1997) and Büyükgüzel et al. (2007) describe the immuneinterference of indomethacin, and in addition to our observations of indomethacin-induced gut impairment, we consider that eicosanoid-like signalling should be added to the list of functional similarities between the innate immune systems of insects and vertebrates.

\section{Galleria mellonella as an alternative animal model}

The fruit fly Drosophila melanogaster is a superior genetic resource and over the past decade has been manipulated to gain novel insight into stem cell fate, immunity, antibiosis and homeostasis in the gut (Buchon et al. 2009; Chandler et al. 2011; Broderick and Lemaitre 2012; Miguel-Aliaga et al. 2018). Only recently, the genome of G. mellonella was made available (Lange et al. 2018a), yet it stands unannotated. Furthermore, despite wax-moth larvae being used widespread as a screening tool for novel therapeutics, pathogenicity, and toxicology (reviewed by Tsai et al. 2016), there remains a historical lag in molecular resources with the exception of some transcriptomic and miRNA data (Vogel et al. 2011; Mukherjee and Vilcinskas 2014). The financial and ethical incentives for using insect larvae over rodents and zebrafish are attractive, and so, we propose that vertebrates could be replaced partially for gut pathobiology. Waxmoth larvae are larger than traditional models like nematodes and drosophilids - this has two distinct advantages: (1) accurate doses can be administered orally (force-feeding), and (2) gram quantities of gut tissue can be obtained easily for downstream processing. Unlike other insect orders, the midgut of lepidopteran larvae represent the majority of tissue along the alimentary canal (mouth to anus; Fig. 4) 
and contains a specialised cell type, namely the goblet cell (Fig. 6), which is also found in the human intestine (Engel and Moran 2013; Linser and Dinglasan 2014).

The most common larval inoculation technique is intrahaemocoelic injection of test compounds/microbes; however, force-feeding G. mellonella (i.e., gavage) is an emerging practice. When screening common food preservatives (e.g., potassium nitrate), Maguire et al. (2016) obtained comparable toxicology data $\left(\mathrm{LD}_{50}\right)$ between insect larvae, human cell lines (HEp-2) and rats. We recently provided evidence that larvae can also be used to assess the lethality and putative immune-toxicological effects of shellfish poisoning toxins (e.g., okadaic acid) at FDA-regulated levels in contaminated foods (Coates et al. 2019). Okadaic acid that was force-fed to insects disrupted midgut homeostasis, leading to detrimental levels of lipid peroxidation (malondialdehyde accumulation) in a dose-dependent manner-resembling symptoms found often in the standardised mouse bioassay. Lange et al. (2018b) proved that G. mellonella could differentiate between an enteric symbiont (Bacteroides vulgatus) and pathobiont (Escherichia coli), and mount a strong immune response involving reaction oxygen/nitrogen species. Oral administration of the pathogen stimulated the up-regulation of immune-recognition genes in insects (e.g., apolipophorin III) and mice (e.g., Cd14) alike. Interestingly, oral exposure of G. mellonella larvae to caffeine led to elevated levels of theobromine and theophylline in the haemolymph-suggesting that caffeine metabolism in this insect is similar to the process in mammals (Maguire et al. 2017).

A better understanding of G. mellonella's alimentary canal should assist insecticide development (e.g., boric acid and biopesticides, Büyükgüzel et al. 2013; Grizanova et al. 2014) as lepidopteran insects represent a sizeable number of devastating agricultural pests (e.g., Spodoptera littoralis; Linser and Dinglasan 2014). A key difference between the digestive systems of vertebrates and insects is the presence of phenoloxidase (PO) enzymes (Whitten and Coates 2017). Phenoloxidases are responsible for the early processing of pigment precursors (quinones) into melanin, which plays several roles in development and immunity. Insect faeces are melanised upon release, and although the function of this is unclear, presumably it is due to gut phenoloxidase-activities and their oxidising/nitrosative by-products maintaining resident microbial populations from over-growing (Whitten and Coates 2017). The gut microbiomes of insects are diverse and tend to be species specific-influenced invariably by diet and environmental factors (Engel and Moran 2013). Few studies have focussed on the G. mellonella gut microbiome, yet representatives of the Bacteroidetes, Firmicutes and Proteobacteria are homologous to the biota on microvilli of the human intestinal crypts (Mukherjee et al. 2013b; Dubovskiy et al. 2016). Further work is needed to profile the residents of the insect gut, including fungi, viruses and Archaea. This is a timely topic, as wax-moth larvae are capable of degrading plastic (polypropylene; Bombelli et al. 2017)—likely facilitated by the microbial consortium of their alimentary canal.

\section{Concluding remarks}

We investigated the physiological effects of indomethacin on G. mellonella, providing compelling evidence that indomethacin exposure leads to tissue damage, cell death, gut leakiness, and REDOX imbalance in insect larvae. This mimics closely the pathological symptoms of their rodent counterparts. We describe the functional/structural similarities of lepidopteran midgut tissues to those found in regions of the human gastrointestinal tract. Our data reinforce the use of G. mellonella as a surrogate toxicology model, with a focus on screening nutraceuticals and food additives.

Acknowledgements This research has been released as a pre-print (Emery et al. 2019) and is available at bioRxiv; https://www.biorx iv.org/content/10.1101/606319v1. We would like to thank Mrs Sophie Malkin (Bluefish Technical Officer, Swansea University) for her assistance with histology preparations, Dr Christopher B Cunningham (Swansea University) for helpful discussions, and Elizabeth Evans and Ria Mitchell (AIM Facility) for helpful tips with image data/ segmentation.

Author contribution CJC conceived/designed all the experiments. HE performed the experiments with assistance from CJC, AFR and RJ. HE collated the data. HE and CJC analysed and interpreted the data. CJC prepared the manuscript, with input from HE, AFR and RJ.

Funding Financial support was secured through the European Social Fund (ESF) KESS2 scheme, and supplemented via start-up funds (College of Science, Swansea University) assigned to CJC. HE is the recipient of a KESS2 PhD scholarship, which is co-sponsored by Mr John Rolfs (The Golden Dairy Ltd.). AFR is part-funded through the joint BBSRC/NERC Aquaculture Collaboration Hub UK (BB/P017215/1). The X-ray work is supported by the Advanced Imaging of Materials (AIM) Facility (EPSRC Grant No. EP/M028267/1) and the ESF through the European Union's Convergence programme administered by the Welsh Government.

\section{Compliance with ethical standards}

Ethics statement This study was approved by the College of Science (Swansea University) research ethics committee (SU-ethics-120218/470).

Conflict of interest The authors declare that they have no conflict of interest.

Open Access This article is distributed under the terms of the Creative Commons Attribution 4.0 International License (http://creativeco mmons.org/licenses/by/4.0/), which permits unrestricted use, distribution, and reproduction in any medium, provided you give appropriate credit to the original author(s) and the source, provide a link to the Creative Commons license, and indicate if changes were made. 


\section{References}

Abràmoff MD, Magalhães PJ, Ram SJ (2004) Image processing with ImageJ. Biophot Int 11(7):36-42

Aguwa CN (1985) Incidence of gastric ulcers by indomethacin and piroxicam in rats. Arch Toxicol 56(3):212-213

Allegra E, Titball RW, Carter J, Champion OL (2018) Galleria mellonella larvae allow the discrimination of toxic and non-toxic chemicals. Chemosphere 198:469-472

Altincicek B, Linder M, Linder D, Preissner KT, Vilcinskas A (2007) Microbial metalloproteinases mediate sensing of invading pathogens and activate innate immune responses in the lepidopteran model host Galleria mellonella. Infect Immun 75(1):175-183

Barnoy S, Gancz H, Zhu Y, Honnold CL, Zurawski DV, Venkatesan MM (2017) The Galleria mellonella larvae as an in vivo model for evaluation of Shigella virulence. Gut Microbe 8(4):335-350

Basivireddy J, Jacob M, Ramamoorthy P, Pulimood AB, Balasubramanian KA (2003) Indomethacin-induced free radical-mediated changes in the intestinal brush border membranes. Biochem Pharmacol 65(4):683-695

Bjarnason I, Takeuchi K (2009) Intestinal permeability in the pathogenesis of NSAID-induced enteropathy. J Gastroenterol 44(19):23-29

Bombelli P, Howe CJ, Bertocchini F (2017) Polyethylene bio-degradation by caterpillars of the wax moth Galleria mellonella. Curr Biol 27(8):R292-R293

Broderick NA, Lemaitre B (2012) Gut-associated microbes of Drosophila melanogaster. Gut Microbe 3(4):307-321

Browne N, Heelan M, Kavanagh K (2013) An analysis of the structural and functional similarities of insect hemocytes and mammalian phagocytes. Virulence 4(7):597-603

Brune K, Patrignani P (2015) New insights into the use of currently available non-steroidal anti-inflammatory drugs. J Pain Res 8:105-118. https://doi.org/10.2147/JPR.S75160

Buchon N, Broderick NA, Poidevin M, Pradervand S, Lemaitre B (2009) Drosophila intestinal response to bacterial infection: activation of host defense and stem cell proliferation. Cell Host Microbe 5(2):200-211

Butt TM, Coates CJ, Dubovskiy IM, Ratcliffe NA (2016) Entomopathogenic fungi: new insights into host-pathogen interactions. Adv Genet 94:307-364

Büyükgüzel E, Tunaz H, Stanley D, Büyükgüzel K (2007) Eicosanoids mediate Galleria mellonella cellular immune response to viral infection. J Insect Physiol 53(1):99-105

Büyükgüzel E, Büyükgüzel K, Snela M, Erdem M, Radtke K, Ziemnicki K, Adamski Z (2013) Effect of boric acid on antioxidant enzyme activity, lipid peroxidation, and ultrastructure of midgut and fat body of Galleria mellonella. Cell Biol Toxicol 29(2):117-129

Campbell PM, Cao AT, Hines ER, East PD, Gordon KH (2008) Proteomic analysis of the peritrophic matrix from the gut of the caterpillar, Helicoverpa armigera. Insect Biochem Mol Biol 38(10):950-958

Card R, Vaughan K, Bagnall M, Spiropoulos J, Cooley W, Strickland $\mathrm{T}$ et al. (2016) Virulence characterisation of Salmonella enterica isolates of differing antimicrobial resistance recovered from UK livestock and imported meat samples. Front Microbiol 7:640

Champion OL, Wagley S, Titball RW (2016) Galleria mellonella as a model host for microbiological and toxin research. Virulence 7(7):840-845

Chandler JA, Lang JM, Bhatnagar S, Eisen JA, Kopp A (2011) Bacterial communities of diverse Drosophila species: ecological context of a host-microbe model system. PLoS Genet 7(9):e1002272

Coates CJ, Lim J, Harman K, Rowley AF, Griffiths DJ, Emery H, Layton W (2019) The insect, Galleria mellonella, is a compatible model for evaluating the toxicology of okadaic acid. Cell Biol Toxicol 35(3):219-232

Cools F, Torfs E, Aizawa J, Vanhoutte B, Maes L, Caljon G et al. (2019) Optimization and characterization of a Galleria mellonella larval infection model for virulence studies and the evaluation of therapeutics against Streptococcus pneumoniae. Front Microbiol 10:311. https://doi.org/10.3389/fmicb.2019.00311

Dubovskiy IM, Martemyanov VV, Vorontsova YL, Rantala MJ, Gryzanova EV, Glupov VV (2008) Effect of bacterial infection on antioxidant activity and lipid peroxidation in the midgut of Galleria mellonella L. larvae (Lepidoptera, Pyralidae). Comp Biochem Physiol C 148(1):1-5

Dubovskiy IM, Grizanova EV, Whitten MM, Mukherjee K et al. (2016) Immuno-physiological adaptations confer wax moth Galleria mellonella resistance to Bacillus thuringiensis. Virulence 7(8):860-870

Engel P, Moran NA (2013) The gut microbiota of insects-diversity in structure and function. FEMS Microbiol Rev 37(5):699-735

Gornall AG, Bardawill CJ, David MM (1949) Determination of serum proteins by means of the biuret reaction. J Biol Chem 177(2):751-766

Green LF, Bergquist PR, Bullivant S (1980) The structure and function of the smooth septate junction in a transporting epithelium: the Malpighian tubules of the New Zealand glow-worm Arachnocampa luminosa. Tissue Cell 12(2):365-381

Grizanova EV, Dubovskiy IM, Whitten MMA, Glupov VV (2014) Contributions of cellular and humoral immunity of Galleria mellonella larvae in defence against oral infection by Bacillus thuringiensis. J Invertbr Pathol 119:40-46

Kloezen W, van Helvert-van Poppel M, Fahal AH, van de Sande WW (2015) A Madurella mycetomatis grain model in Galleria mellonella larvae. PLoS Neglect Trop D 9(7):e0003926

Kuraishi T, Binggeli O, Opota O, Buchon N, Lemaitre B (2011) Genetic evidence for a protective role of the peritrophic matrix against intestinal bacterial infection in Drosophila melanogaster. Proc Nat Acad Sci 108(38):15966-15971

Lange A, Beier S, Huson DH, Parusel R, Iglauer F, Frick JS (2018a) Genome sequence of Galleria mellonella (greater wax moth). Genome Announc 6(2):e01220-e01317. https://doi.org/10.1128/ genomeA.01220-17

Lange A, Schäfer A, Bender A, Steimle A, Beier S, Parusel R, Frick JS (2018b) Galleria mellonella: a novel invertebrate model to distinguish intestinal symbionts from pathobionts. Front Immunol 9:2114. https://doi.org/10.3389/fimmu.2018.02114

Lim J, Coates CJ, Seoane PI, Garelnabi M, Taylor-Smith LM et al (2018) Characterizing the mechanisms of nonopsonic uptake of Cryptococci by macrophages. J Immunol 200(10):3539-3546. https://doi.org/10.4049/jimmunol.1700790

Limaye A (2012) Drishti: a volume exploration and presentation tool. In: Developments in X-ray Tomography VIII. International Society for Optics and Photonics (Vol. 8506, p. 85060X)

Linser PJ, Dinglasan RR (2014) Insect gut structure, function, development and target of biological toxins. Adv Insect Physiol 47:1-37

Maguire R, Duggan O, Kavanagh K (2016) Evaluation of Galleria mellonella larvae as an in vivo model for assessing the relative toxicity of food preservative agents. Cell Biol Toxicol 32(3):209-216

Maguire R, Kunc M, Hyrsl P, Kavanagh K (2017) Caffeine administration alters the behaviour and development of Galleria mellonella larvae. Neurotoxicol Teratol 64:37-44

Mahmood A, Fitzgerald AJ, Marchbank T, Ntatsaki E, Murray D, Ghosh S, Playford RJ (2007) Zinc carnosine, a health food supplement that stabilises small bowel integrity and stimulates gut repair processes. Gut 56(2):168-175

Mandato CA, Diehl-Jones WL, Moore SJ, Downer RG (1997) The effects of eicosanoid biosynthesis inhibitors on prophenoloxidase 
activation, phagocytosis and cell spreading in Galleria mellonella. J Insect Physiol 43(1):1-8

Marchbank T, Ojobo E, Playford CJ, Playford RJ (2011) Reparative properties of the traditional Chinese medicine Cordyceps sinensis (Chinese caterpillar mushroom) using HT29 cell culture and rat gastric damage models of injury. Br J Nutr 105(9):1303-1310

Matsui H, Shimokawa O, Kaneko T, Nagano Y, Rai K, Hyodo I (2011) The pathophysiology of non-steroidal anti-inflammatory drug (NSAID)-induced mucosal injuries in stomach and small intestine. J Clinical Biochem Nutr 48(2):107-111

Miguel-Aliaga I, Jasper H, Lemaitre B (2018) Anatomy and physiology of the digestive tract of Drosophila melanogaster. Genetics 210(2):357-396

Mowlds P, Coates C, Renwick J, Kavanagh K (2010) Dose-dependent cellular and humoral responses in Galleria mellonella larvae following $\beta$-glucan inoculation. Microbes Infect 12(2):146-153

Mukherjee K, Vilcinskas A (2014) Development and immunity-related microRNAs of the lepidopteran model host Galleria mellonella. BMC Genomics 15(1):705

Mukherjee K, Hain T, Fischer R, Chakraborty T, Vilcinskas A (2013a) Brain infection and activation of neuronal repair mechanisms by the human pathogen Listeria monocytogenes in the lepidopteran model host Galleria mellonella. Virulence 4(4):324-332

Mukherjee K, Raju R, Fischer R, Vilcinskas A (2013b) Galleria mellonella as a model host to study gut microbe homeostasis and brain infection by the human pathogen Listeria monocytogenes. In: Vilcinskas A (ed) Yellow biotechnology I. Springer, Berlin, Heidelberg, pp 27-39

Perron N, Tremblay E, Ferretti E, Babakissa C, Seidman E et al (2013) Deleterious effects of indomethacin in the mid-gestation human intestine. Genomics 101(3):171-177

Playford RJ, Floyd DN, MacDonald CE, Calnan DP, Adenekan RO et al (1999) Bovine colostrum is a health food supplement which prevents NSAID induced gut damage. Gut 44(5):653-658

Playford RJ, MacDonald CE, Calnan DP, Floyd DN, Podas T et al (2001) Co-administration of the health food supplement, bovine colostrum, reduces the acute non-steroidal anti-inflammatory drug-induced increase in intestinal permeability. Clin Sci 100(6):627-633

Renwick J, Reeves EP, Wientjes FB, Kavanagh K (2007) Translocation of proteins homologous to human neutrophil p47phox and p67phox to the cell membrane in activated hemocytes of Galleria mellonella. Dev Comp Immunol 31(4):347-359

Senior NJ, Bagnall MC, Champion OL, Reynolds SE, La Ragione RM et al (2011) Galleria mellonella as an infection model for Campylobacter jejuni virulence. J Med Microbiol 60(5):661-669

Sigthorsson G, Crane R, Simon T, Hoover M, Quan H, Bolognese J, Bjarnason I (2000) COX-2 inhibition with rofecoxib does not increase intestinal permeability in healthy subjects: a double blind crossover study comparing rofecoxib with placebo and indomethacin. Gut 47(4):527-532

Smecuol E, Bai JC, Sugai E, Vazquez H, Niveloni S et al (2001) Acute gastrointestinal permeability responses to different non-steroidal anti-inflammatory drugs. Gut 49(5):650-655

Strober W (2015) Trypan blue exclusion test of cell viability. Curr Protoc Immunol. https://doi.org/10.1002/0471142735.ima03bs111

Tsai CJY, Loh JMS, Proft T (2016) Galleria mellonella infection models for the study of bacterial diseases and for antimicrobial drug testing. Virulence 7(3):214-229

Vogel H, Altincicek B, Glöckner G, Vilcinskas A (2011) A comprehensive transcriptome and immune-gene repertoire of the lepidopteran model host Galleria mellonella. BMC Genomics 12(1):308

Wagley S, Borne R, Harrison J, Baker-Austin C, Ottaviani D et al (2018) Galleria mellonella as an infection model to investigate virulence of Vibrio parahaemolyticus. Virulence 9(1):197-207

Whitten MMA, Coates CJ (2017) Re-evaluation of insect melanogenesis research: views from the dark side. Pigment Cell Melanoma Res 30(4):386-401

Publisher's Note Springer Nature remains neutral with regard to jurisdictional claims in published maps and institutional affiliations. 